\title{
NEURON-SPECIFIC ENOLASE AS AN INDEX OF NEURONAL REGENERATION AND REINNERVATION ${ }^{1}$
}

\author{
TAKAAKI KIRINO, ${ }^{*}, 2$ MILTON W. BRIGHTMAN, ${ }^{*},{ }^{3}$ WOLFGANG H. OERTEL, ${ }^{4}$ \\ DONALD E. SCHMECHEL, $\neq^{5}$ AND PAUL J. MARANGOS $\ddagger^{6}$ \\ * Laboratory of Neuropathology and Neuroanatomical Sciences and $\ddagger$ Laboratory of Clinical Sciences, National Institutes of \\ IIealth, Bethesda, Maryland 20205
}

Received August 3, 1982; Revised October 18, 1982; Accepted November 9, 1982

\begin{abstract}
Neuron-specific enolase (NSE) is a glycolytic isoenzyme which is located in central and peripheral neurons and neuroendocrine cells. Another enolase isoenzyme, non-neuronal enolase (NNE), occurs in glial cells. The purpose of this study was to follow any changes in NSE and/or NNE in cranial motor neurons after separation of their cell bodies from their axon terminals. One hypoglossal nerve in the rat and the cynomolgus monkey was thus crushed or cut and, after a given period, the brains were perfusion fixed. Immunocytochemistry, using anti-rat NSE and NNE or anti-human NSE and NNE, was performed on Vibratome-sectioned specimens of the hypoglossal nuclei. In the rat, NSE immunostaining decreased in the affected neurons 2 to 10 days following axonal injury. The change was greatest on the 10th day. Twenty days following nerve crush, NSE staining began to recover on the operated side and by the 45th day had returned to normal levels. NSE changes in the monkey were similar to those in the rat. In rats, where the nerve was cut and the proximal stump was translocated to a normally innervated muscle to inhibit re-formation of synaptic contacts, the NSE remained low for 60 days after nerve injury. As NSE levels fell during degeneration, there was a slight increase in NNE in some of the monkey specimens but not in others; the NNE alterations were, therefore, equivocal. 'T'he results demonstrate that the content of NSE' in neurons serves as a molecular marker of axon injury, regeneration, and target reinnervation.
\end{abstract}

Neuron-specific enolase (NSE; EC 4.2.1.11) is an acidic, soluble protein (Marangos and Schmechel, 1980; Zomzely-Neurath and Walker, 1980) which functions as a glycolytic isoenzyme (Bock and Dissing, 1975) and is homologous to bovine 14-3-2 protein characterized by Moore and McGregor (1965). Immunocytochemical surveys have demonstrated that NSE is confined solely to neurons (Pickel et al., 1976), not only central ones but those of dorsal root ganglia, autonomic ganglia, and some peripheral neuroendocrine cells as well. NSE can be used, therefore, as an identifying molecular marker for all types of neurons in vivo and in vitro (Schmechel et al., 1978a).

\footnotetext{
'We are grateful to Virginia K. Weise and Alexandra M. Parma of the Laboratory of Clinical Sciences, National Institutes of Health, for their competent technical assistance.

${ }^{2}$ Present address: Department of Neurosurgery, University of Tokyo Hospital, Tokyo, Japan.

${ }^{3}$ To whom requests for reprints should be sent.

${ }^{4}$ Present address: Neurologische Klinik, Munich, West Germany.

${ }^{5}$ Present address: Neurology Department, Duke University Medical School, Durham, NC 27710.

${ }^{6}$ Present address: Laboratory of Clinical Psychobiology, National Institutes of Health, Bethesda, MD 20205.
}

Glial cells, on the other hand, have a different enolase isoenzyme. This glial or non-neuronal enolase (NNE) is thought to be identical to liver enolase (Marangos and Schmechel, 1980). NNE has been demonstrated within astrocytes, oligodendrocytes, ependyma, and choroid plexus epithelia and can thus serve as a marker for glial cells (Schmechel et al., 1978a).

In the developing nervous system, however, this simple enzyme dichotomy: NSE - neurons, NNE - glia, is not applicable. According to biochemical assays, NNE is dominant at first in developing brain and, later, NSE becomes ascendant (Marangos et al., 1978a). Cerebellar granule cells have immunocytochemically detectable NNE while they are still in the external granular layer, but they acquire their normal NSE content as they migrate down to the internal granular layer and form synapses. In other words, neurons switch from NNE to NSE as they differentiate (Schmechel et al., 1980b). The NSE antigen is thus an excellent marker for neuronal differentiation.

Neurons undergo a certain sequence of morphological and metabolic changes following axonal injury (Lieberman, 1971; Grafstein and McQuarrie, 1978). It is believed that neurons shift, after axonal injury, to the immature 
"growing phase" from the differentiated "secretory phase" (Jacobson, 1978). It might be assumed that dedifferentiation takes place following axotomy and that differentiation resumes during nerve regeneration. The purpose of these experiments was 3-fold: to see whether the level of NSE changes in response to axotomy, whether there is a shift from NSE to NNE that would thus resemble a dedifferentiated or developmental state, and whether the restoration of NSE levels depends on the axon's reinnervation of its target.

\section{Materials and Methods}

With radioimmunoassay of $N \mathrm{NE}$, a modest change in the neuronal content of this enzyme could well be masked by the NNE content of surrounding glial cells. Moreover, the relatively densely stained NSE of the ventral part of the hypoglossal nucleus, regardless of treatment, could easily be included in variable amounts within a punch sample for radioimmunoassay and could mask changes in levels of NSE. Thus, in order to detect changes in neuronal NNE and NSE, immunocytochemistry rather than radioimmunoassay for these enzymes was used.

Antisera against purified rat NSE and NNE or human NSE and NNE were prepared in New Zealand White rabbits as previously described (Marangos et al., 1975a, b). No cross-reactivity of anti-NSE with NNE or antiNNE with NSE was observed (Marangos et al., 1978b).

Changes in NSE content were estimated by comparing the operated side with the immediately adjacent unoperated side in each section. The slides were coded by one observer and two other observers (W. O. and D. S.) evaluated the sections without knowledge of their source.

Rats. Adult (45-day-old) male Osborne-Mendel rats were anesthetized with fluothane. The right hypoglossal nerve (12th nerve) trunk was exposed beneath the posterior belly of the digastric muscle, freed, and manually crushed with a fine forceps (Dumont stainless steel, no. 5) for $1 \mathrm{~min}$. Animals were fixed by perfusion fixation 2 , $5,10,20,30$, and 45 days following this operative procedure. Sham-operated animals, serving as the controls, were fixed 10 days after the operation. At least four animals were included in each group, and a total of 42 rats were used. In another group of 10 adult, male rats of the same strain, the 12 th nerve trunk was cut rather than crushed. In five of them, the severed stumps were anastomosed with 10-0 nylon suture. In the other five rats, the distal stump $(1.0 \mathrm{~mm})$ was removed and the proximal trunk was inserted into the posterior belly of the digastric muscle, the normal innervation of which was left intact, and sealed into place with fascia using a 10-0 suture. These 10 animals were fixed 60 days later. In a third group of thirtecn 9-day-old pups, the 12 th nerve was cut and the severed ends were simply left apposed. They were fixed $2,5,10,20$, and 30 days after axotomy.

The fixative consisted of $4 \%$ paraformaldehyde, $1 \%$ glutaraldehyde, $0.2 \%$ picric acid, and $2 \%$ sucrose in $0.1 \mathrm{M}$ sodium acetate buffer, pH 6.0 (Schmechel et al., 1980a). Two hours after perfusion fixation, the brains were removed from the skull and kept in the same fixative at $4^{\circ} \mathrm{C}$ for $3 \mathrm{hr}$ then transferred to Tris-buffered saline (TBS; $150 \mathrm{~mm} \mathrm{NaCl}$ in $50 \mathrm{~mm}$ Tris-HCl buffer, $\mathrm{pH} 7.6$ ). The medulla oblongata was cut into $25-\mu \mathrm{m}$-thick sections on a Vibratome. From each animal, 40 to 60 Vibratome sections containing the hypoglossal nucleus (12th nerve nucleus) were processed for immunocytochemistry using the unlabeled antibody, peroxidase-antiperoxidase

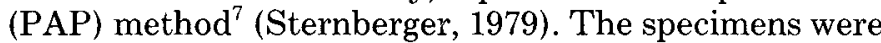
mounted on chrome/alum-coated glass slides after staining and observed with a Zeiss Photomicroscope III. Some sections were embedded in Araldite 502; semithin sections were then cut and lightly stained with toluidine blue.

Monkeys. Since antibody of human NNE reacts with monkey antigen more vigorously than anti-rat NNE does with rat antigen, the experiment was repeated in six adult cynomolgus monkeys (Macaca fascicularis). The right 12 th nerve was cut at the level of the anterior belly of the digastric muscle. At 10, 15, and 20 days following nerve section, the brains were perfusion fixed with the same fixative composition as that used for the rats. The medulla oblongata was removed and processed for immunocytochemistry in the same way, using the antisera against human NSE and NNE. Four different "bleeds" of antisera against human NNE were used for each animal.

\section{Results}

Rats. In sham-operated rats, the bilateral 12 th nerve nuclei were symmetrically stained for NSE. Stainability was almost even throughout the rostral-caudal extent of the 12 th nerve nucleus but the ventral portion, where 12th nerve neurons are most crowded, was slightly but consistently darker. While the neuronal perikaryon was densely colored, the cell nucleus was unstained. The perikaryal cytoplasm was stained inhomogeneously and had a reticular pattern (Fig. 1). In the neuropil around the neurons were scattered numerous fine granular structures which were mostly dendrites and a few axons (Fig. 1). There was a marked variation in staining among these myelinated axons and dendrites (Fig. 1). A myelinated axon could be stained, whereas its immediate neighbor was not. In a single axon or dendrite, the degree of staining diminished in its more distal extent. Glial and endothelial cells were completely devoid of staining (Fig. 1). The 12th nerve neurons, in general, were more lightly stained for NSE than were the reticular neurons at the same level of the medulla oblongata. These staining properties were maintained on the unoperated side through the experiment (Fig. 6). In the dorsal part of the 12 th nerve nucleus, there were always a few fusiform

\footnotetext{
${ }^{7}$ The method was as follows: (1) $5 \mathrm{~min}$ in $10 \%$ methanol and $3 \%$ $\mathrm{H}_{2} \mathrm{O}_{2}$ in TBS. (2) $5 \mathrm{~min}$ in $0.25 \%$ Triton X-100 in TBS. (3) $60 \mathrm{~min}$ in a solution containing $10 \%$ normal sheep serum (NSS) and $0.1 \mathrm{M}$ crystalline DL-lysine in TBS. (4) $2 \mathrm{hr}$ in the solution of anti-rat NSE (1:4000 or 1:8000), anti-rat NNE (1:400 or 1:1000), or anti-human NSE (1:400 or 1:800), anti-human NNE (1:400 or 1:800) at room temperature for 16 to $18 \mathrm{hr}$ at $4^{\circ} \mathrm{C}$. Antisera were dissolved in $2 \%$ NSS in TBS. Normal rabbit serum, at the same dilution, was used as controls. (5) $30 \mathrm{~min}$ in the solution of sheep anti-rabbit IgG (1:80) in TBS with $2 \%$ NSS. (6) 30 min in the solution of PAP (1:100) in TBS with $2 \%$ NSS. (7) 5 to 10 min in the solution containing $0.01 \% \mathrm{H}_{2} \mathrm{O}_{2}$ and $0.05 \%$ diaminobenzidine in TBS. Between each step, the specimens were washed several times with TBS.
} 


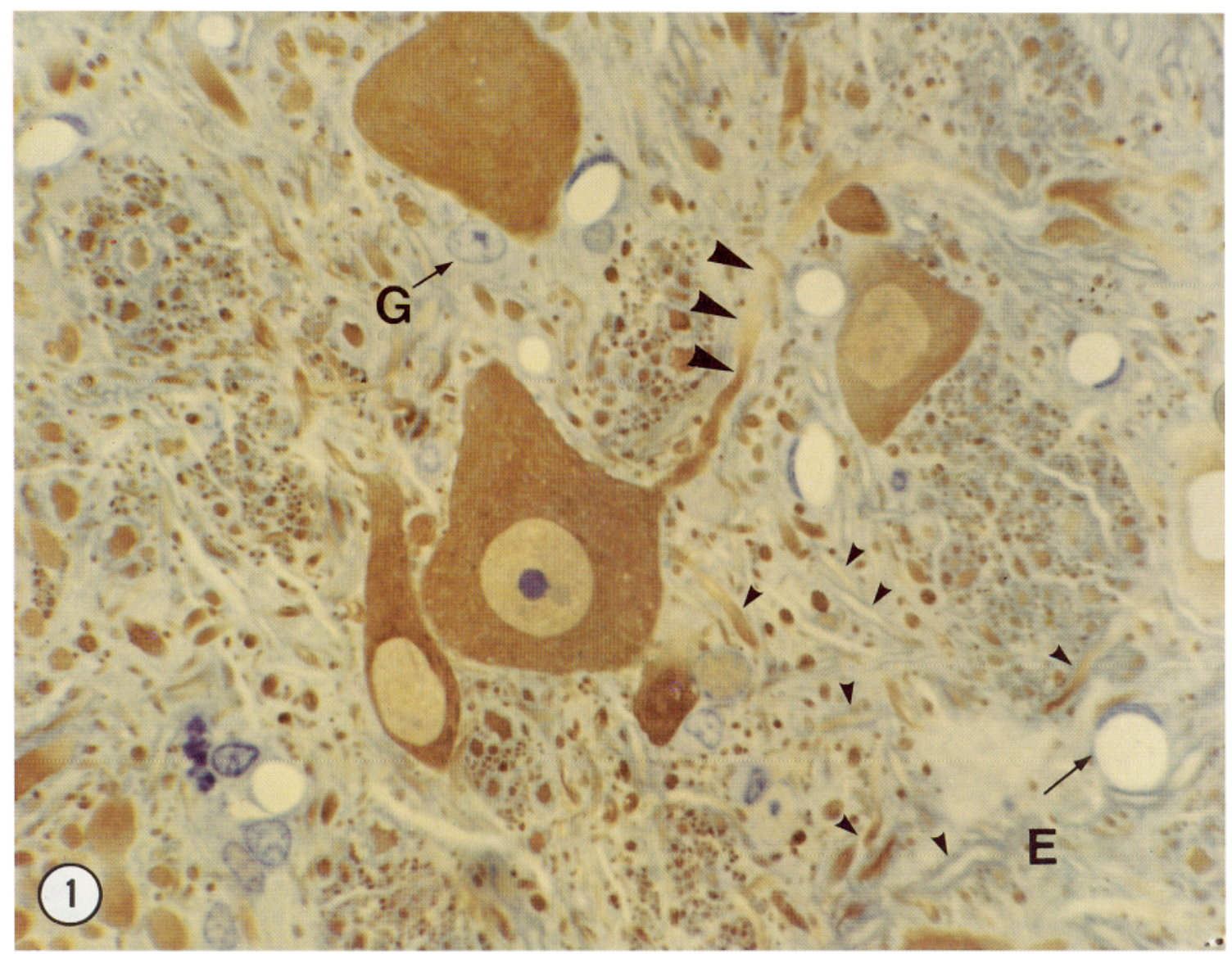

Figure 1. Focal variations in the levels of immunocytochemically detected NSE of the intact rat hypoglossal nucleus. The cytoplasm of the neurons is filled with reaction product. There is marked variation in staining between neighboring axons and dendrites (small arrowheads). In a single neuronal process, staining fades proximodistally (large arrowheads). Glial cells (G) and endothelial $(E)$ are devoid of staining. Plastic embedded specimen, lightly counterstained with toluidine blue. Magnification $\times 800$.

neurons as densely reactive for $\mathrm{NSE}$ as the reticular neurons (Figs. 2 and 4 ).

The first recognizable change in stainability was noted 2 days after the 12th nerve crush when the content of NSE on the operated side decreased slightly. Five days following operation, the neurons and, to a lesser degree, their processes on the affected side were definitely more lightly stained than were those on the unoperated side.

The greatest change in NSE content was noticed 10 days after nerve crush (Fig. 2). In the affected 12th nerve nucleus, distinction between the perikarya and their cell nuclei was less marked due to a decreased staining in the perikarya (Fig. 7). At this stage, the neuronal cell bodies had become slightly swollen (Fig. 7). The cell nuclei of some neurons were often stained exclusively on the affected side (Fig. 2). Axons and dendrites of the neuropil also had a decreased stainability (Fig. 7). As a result, the affected nucleus appeared far lighter than the intact side at low magnification. Although almost all neurons had lost their normal stainability for NSE, a few small, fusiform neurons, horizontally disposed, remained darkly stained (Fig. 2). These neurons, therefore, do not send their axons to the 12th nerve and are probably interneurons.
Twenty days after the 12 th nerve was crushed, the difference between the bilateral 12th nerve nuclei in NSE staining was only slight. However, a part of the affected 12th nerve nucleus had a decreased immunostaining and included a few scattered, lightly stained neurons containing nuclei that were darker than the cytoplasm. Thirty days following the operation, differences in NSE content between both sides were hardly discernible at low magnification, but a few neurons still remained lightly stained. By 45 days, the affected side was no longer distinguishable from the unaffected, opposite side (Fig. 3 ). The NSE content had decreased rapidly and simultaneously in most neurons, but returned to near normal levels rather slowly and asynchronously.

In rats whose 12th nerve had been cut and then anastomosed, the 12th nerve nucleus on the operated side was only minimally shrunken. Sixty days following surgery, NSE stainability had recovered to almost normal levels; only a very few neurons remained lightly stained (Fig. 5). In those rats where the proximal cut end of the 12 th nerve had been inserted into the normally innervated digastric muscle in order to prevent synapse formation, almost all of the hypoglossal neurons on the affected side had a marked depletion of NSE 60 days 

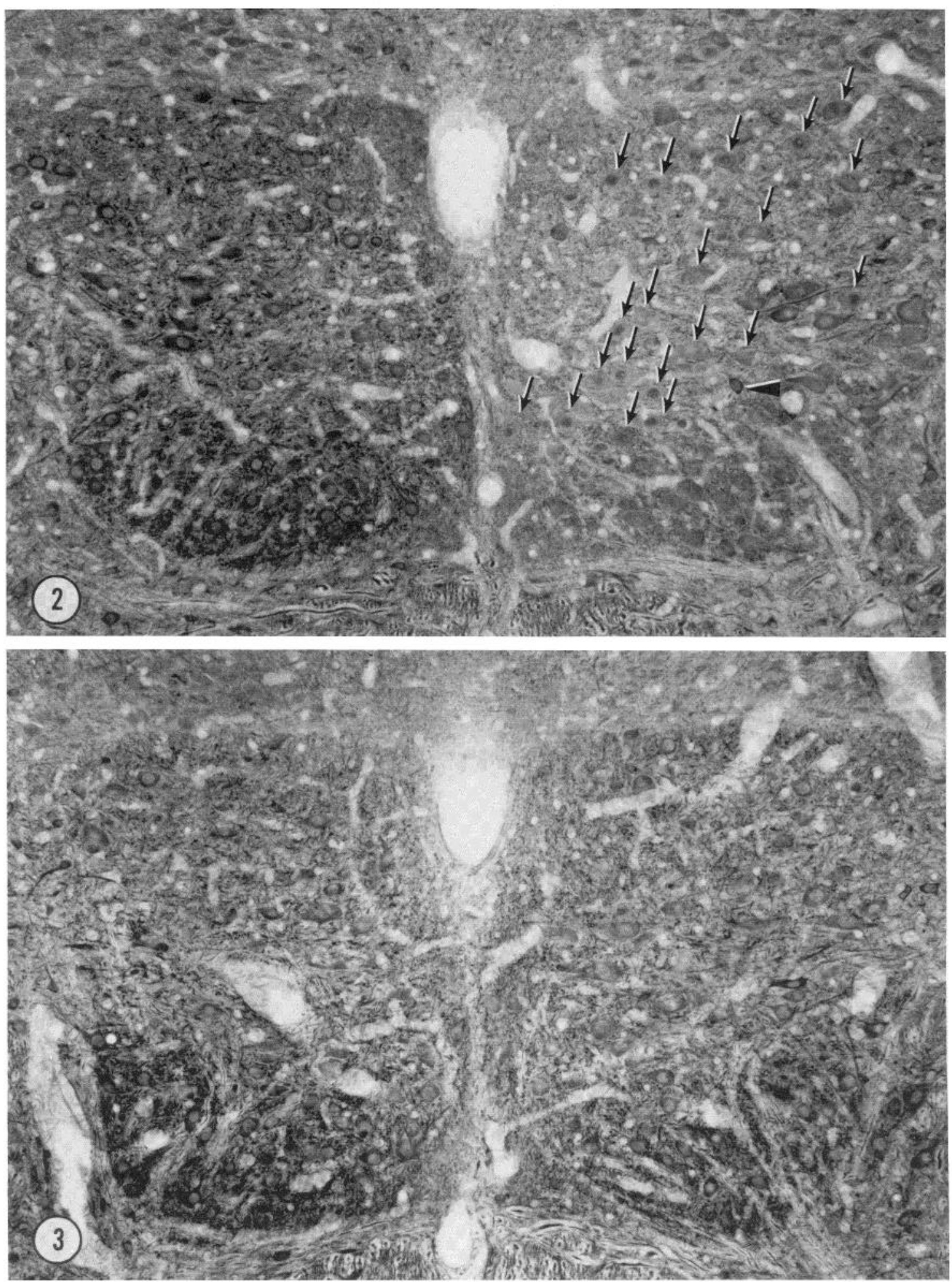

Figures 2 to 5 . The right half is the side of operation. Magnification $\times 130$.

Figure 2. Ten days following 12 th nerve crush. The affected side shows overall decrease in staining. Not only neuronal perikarya but dendrites and axons, which appear as dark granules on the normal side, are only faintly stained. Cell nuclei are distinctly stained only on the affected side (arrows). A small neuron remains still intensely stained (arrowhead). See Figures 6 and 7 for enlargements.

Figure 3. Forty-five days after operation, both sides of 12th nerve nucleus show similar stainability for NSE. No definite shrinkage of the nucleus followed crush injury in adult rats. 

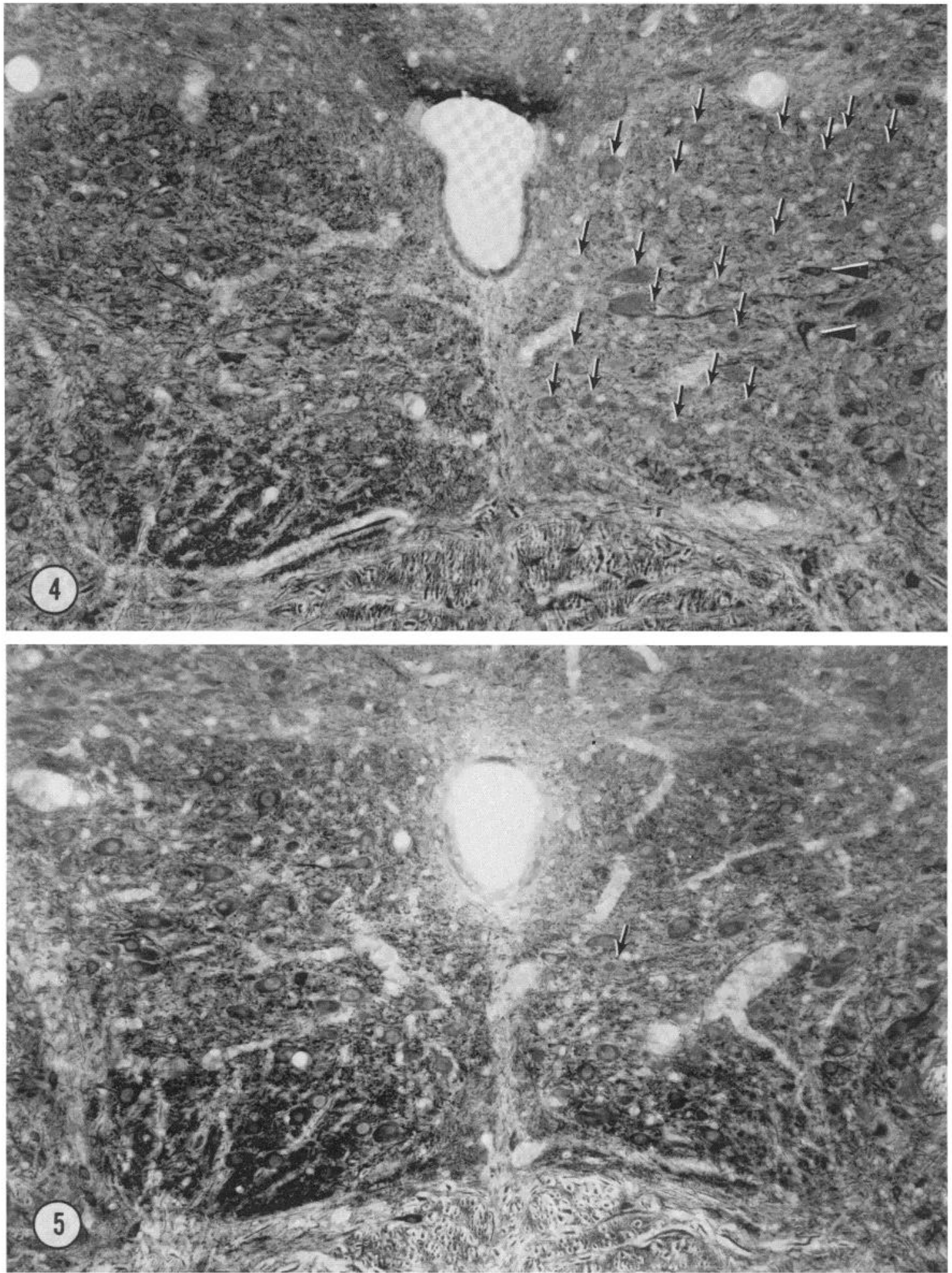

Figure 4. Sixty days after 12th nerve severance. The nerve's proximal stump was relocated to the digastric muscle so that tongue reinnervation was prevented. The affected nucleus was slightly atrophied. Marked reduction of NSE staining on the operated side persists. A few small neurons (arrowheads) are intensely stained.

Figure 5. Sixty days after 12th nerve cut. The 12th nerve has been anastomosed immediately after severance. The degree of atrophy on the operated side is less than that in Figure 4. NSE staining looks normal on the affected side except for one neuron which is lighter and has nuclear staining (arrow).

after operation (Fig. 4). The 12th nerve nucleus was moderately shrunken, while the denervated side of the tongue had become severely atrophied.

In young pups, the 12th nerve nucleus underwent marked shrinkage on the operated side, but the surviving 12th nerve neurons were normally stained for NSE 30 days after 12th nerve interruption (Fig. 8).

Every other section in most of the specimens was also 

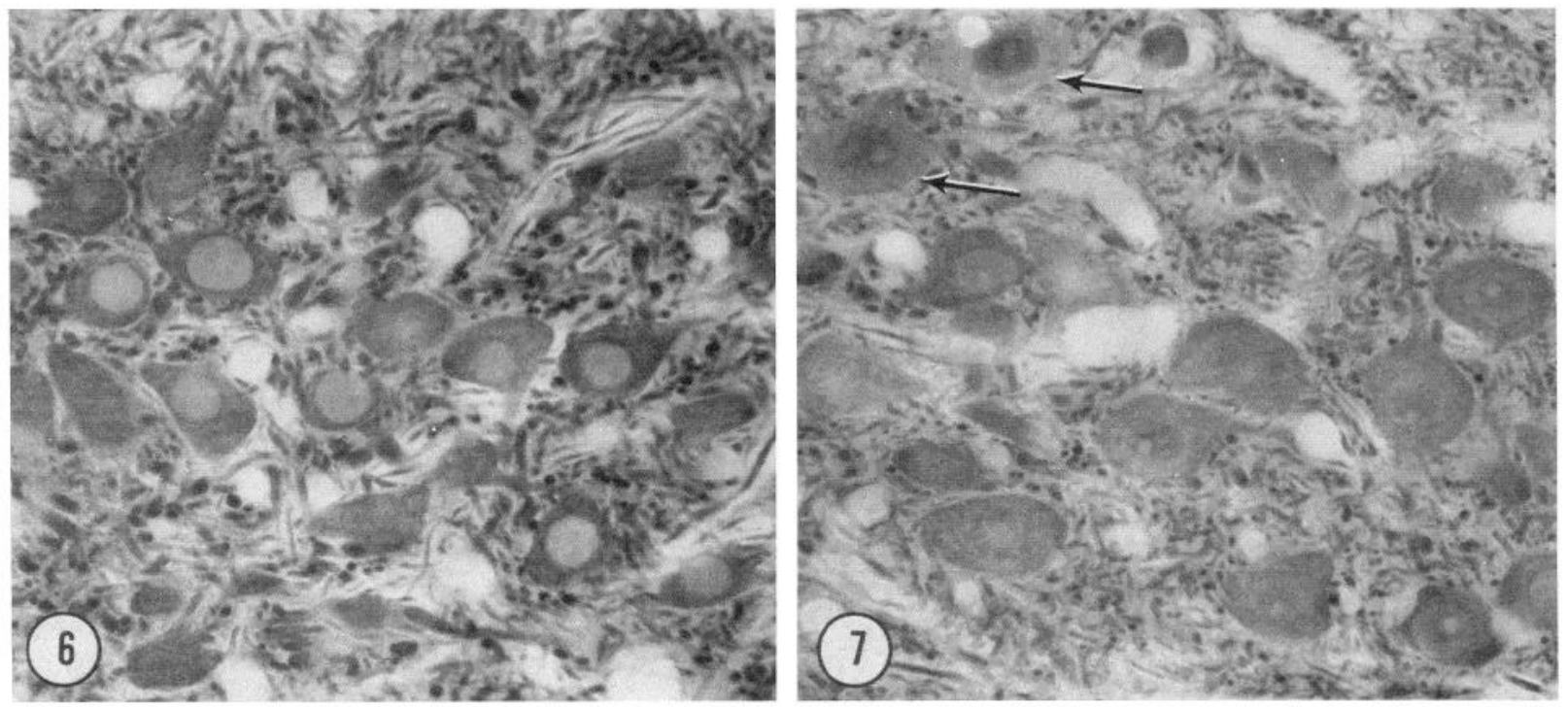

Figures 6 and 7 . Ten days following nerve crush (rat). Magnification $\times 450$.

Figure 6. Control side. Perikarya and cell processes are stained intensely, whereas the cell nuclei are relatively pale.

Figure 7. Operated side. Staining is generally reduced. The nuclei of a few cells are stained (arrows) only in the affected 12 th nerve nucleus. Neuronal processes are thinner.

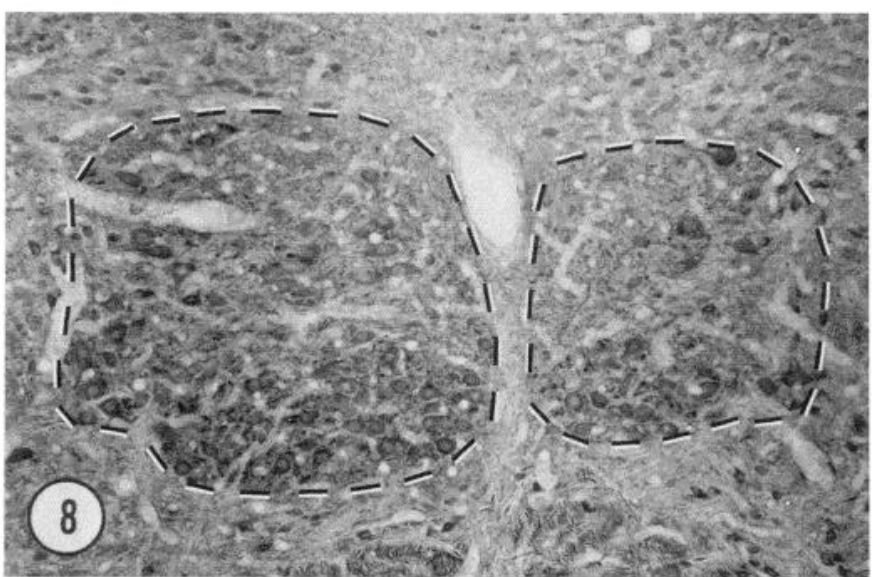

Figure 8 . Thirty days after 12 th nerve section in a young rat (9 days old at the time of surgery). Although the affected nucleus suffers severe atrophy, the remaining 12 th nerve neurons demonstrate a normal pattern of NSE immunostaining. Magnification $\times 80$.

examined for NNE, which was confined primarily to the glial type of cells, although neurons were very lightly stained. Specific antisera against rat NNE failed to demonstrate any consistent changes in NNE content of the 12th nerve nucleus after axonal injury and during nerve regeneration in rats.

Monkeys. NSE reactivity was diminished in the affected 12th nerve nucleus of the monkey as it was in the rat. On the operated side, NSE reaction decreased at all observation periods. The change at 15 days after surgery was the most pronounced (Fig. 9).

Every other section from all of the monkey specimens was examined with four different preparations of antisera against human NNE (Fig. 10). Staining was localized primarily to glial cells, including their fine processes (Fig.
11), and to ependyma. The glial cells were intensely colored. Normal 12th nerve nucleus neurons were themselves very lightly, but perceptibly, stained (Fig. 11).

On the operated side, neurons were moderately stained for NNE (Fig. 12). This neuronal staining for NNE was never intense but was slightly greater on the affected side in some monkeys. The increase in NNE was usually so modest in other specimens as to be equivocal. The cell nuclei in some of these neurons were also stained (Fig. 12).

\section{Discussion}

This report describes a decrease of NSE immunoreactivity in hypoglossal neurons following axonal injury and restoration of NSE immunoreactivity to normal levels when regeneration of hypoglossal fibers is known to take place. NSE visualized immunocytochemically can serve, therefore, as a molecular indicator of injury to the axon and of target reinnervation by the regenerating axon.

In the rat, NSE decreased from 2 to 20 days following 12 th nerve crush and was at its lowest on the 10th day. NSE also decreased in the cynomolgus monkey but the change was less pronounced and developed more slowly. Usually, by the 10th day after injury to one hypoglossal nerve in rats, some nerve fibers grow into the tongue muscle to reinnervate motor endplates (Watson, 1968). Thus, at the time NSE was at its lowest level, reinnervation is reported to have just begun. Between 30 and 45 days after axonal crush, NSE levels were restored. This period corresponds to that of complete regeneration of the crushed nerve in the rat (Watson, 1968). The recovery of NSE was delayed in rats whose 12th nerve was cut and re-anastomosed, but eventually, the NSE levels returned to normal.

Significantly, in those rats whose 12th nerve was cut and prevented from establishing new synaptic contacts (Watson, 1970; Sumner, 1976), the NSE of the parent cell 

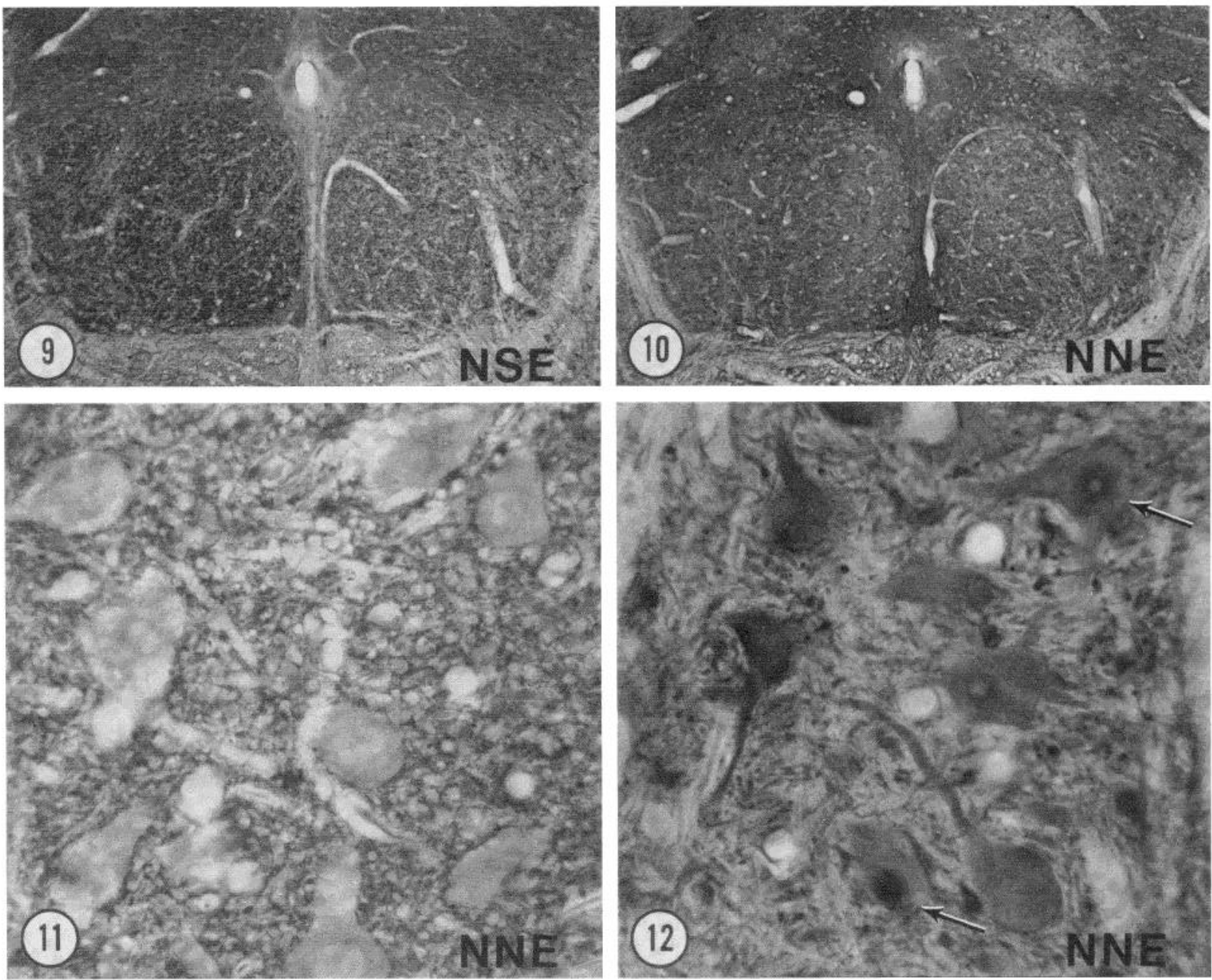

Figures 9 to 12. NSE and NNE staining in the cynomolgus monkey 15 days after unilateral 12th nerve severance. Operated sides are on the right in Figures 9 and 10.

Figure 9. There is a definite decrease in staining on the operated side. Magnification $\times 40$.

Figure 10. There is no distinct difference between the two sides at this magnification $(\times 40)$, partly because of the background staining of glial processes.

Figure 11. Magnification of Figure 10 (normal side). Glial processes appear as a densely stained network surrounding neurons and their processes which are faintly stained. Magnification $\times 350$.

Figure 12. Magnification of Figure 10 (affected side). Increased NNE staining in 12th nerve neurons. The nuclei of some neurons are densely stained (arrows). In other parts of the hypoglossal nucleus, there was no increase in NNE staining. Magnification $\times 350$.

bodies remained at a low level. The full recovery of NSE content seemed to depend on a more or less complete reformation of myoneural contacts.

Parallel studies on NNE immunoreactivity in monkeys revealed in some specimens a discernible rise in NNE staining intensity concurrent with the decline in NSE immunoreactivity. Nevertheless, the staining of regenerating neurons for NNE in other rat and monkey specimens was not appreciably greater than normal. This variable response makes questionable the reality of the minor increase in NNE staining.

One probable reason for the decline in NSE may be a redirection of synthesis away from NSE to other proteins. Reports on patterns of protein synthesis after axonal injury, however, have revealed disparate results. On one hand, enzyme proteins, such as those involved in transmitter metabolism, decrease after axotomy (see Graf- stein, 1975 , for summary). The specific activities of some glycolytic enzymes are reduced about $30 \%, 10$ days after sectioning of the postganglionic axons of the superior cervical ganglion (SCG). This decrement was believed to be part of a general decline in protein concentration (Harkonen and Kaufman, 1974). In a sensory systemthe fourth order neurons in cortical barrel fields-the activity of several enzymes also decreased after injury to the first order neurons (Wong-Riley and Welt, 1980; Dietrich et al., 1981). This decrease has been attributed to a decline in metabolic activity because of disuse.

Other studies indicate that axon injury may lead to heightened protein synthesis. Ten days after axon injury, during the "outgrowth" phase of axon regeneration, synthesis of protein in the rabbit's hypoglossal nucleus was enhanced (Brattgard et al., 1957; Agranoff et al., 1980). In the SCG, both augmented and diminished synthetic 
rates of different proteins accompanied nerve regeneration. Axon injury lead to augmented synthesis of 16 unidentified proteins but a diminished production of 5 others. Synthesis of actin was heightened, whereas tublin was statistically insignificant from control levels (Hall et al., 1978). It remains to be shown whether a dichotomy of synthesis exists whereby structural proteins are produced at a higher rate than are certain enzymes.

The functional significance of the transient decline in NSE has yet to be determined. NSE comprises almost $3 \%$ of all soluble proteins in the neuron (Marangos and Schmechel, 1980). The reason for this excess of enzyme is not known. Since NSE is apparently not a rate-limiting enzyme in the glycolytic pathway (Zomzely-Neurath and Walker, 1980), it is conceivable that a decreased amount of NSE is still sufficient to meet the requirements for augmented metabolism. In such cases, however, we have to postulate that intact neurons have a glycolytic enzyme far in excess of that which is needed, or that NSE has a different metabolic role in normal neurons. Such a different role might be indicated by the point-to-point variation in NSE staining between neighboring axons and dendrites and within a given process, where the decrement in staining proceeds distally. Moreover, a slight increase in NNE levels, if it does take place, may be sufficient to meet, temporarily, the metabolic demands of the regenerating neuron.

Neurons lose their normal electrical activity after axotomy and shift from a mature "secretory" form to a "growing" form (Jacobson, 1978). During this stage, energy metabolism apparently increases to meet the requirements for augmented synthesis (Singer and Mahler, 1979), yet the NSE level diminishes.

The fall in NSE content of damaged neurons may be related to a reduced depolarization. After axon injury, the presynaptic terminals impinging upon the soma and dendrites of the affected neurons are reversibly displaced by intervening microglial processes (Blinzinger and Kreutzberg, 1968). The degree of depolarization and, consequently, the amount of chloride ion entering such neurons would be reduced. It has been proposed that NSE, which withstands a high concentration of chloride without becoming denatured, is a stable form of enolase adapted to neuronal activity (Marangos and Schmechel, 1980). Since there would be a fall in the amount of chloride entering axon-damaged neurons, the requirement for NSE would be less than that of normal neurons and could account for the decrement in NSE.

The causes of the fall in NSE can only be surmised. 'The amount of enzyme within the soma at any one time may depend on the transient balance between the rate st which the enzyme is synthesized and its transport from the cell body (Cragg, 1970). An alternative, unsubstantiated possibility for the decline in NSE is an accelerated, anterograde transport of NSE out of the soma and dendrites. A substantial degradation of the enzyme, in response to axon trauma, might also conceivably lead to the decline in NSE. Another possible, but unlikely reason for the fall in NSE could be swelling of the soma as a form of "axon reaction" (Lieberman, 1971) and resultant dilution of $\mathrm{NSF}_{\text {; }}$ however, decreased staining was also detected in dendrites and unswollen neurons. The apparently artifactitious migration of NSE into the cell nucleus of affected neurons may also deplete the cytoplasm of some of its NSE. This redistribution may be due to the nuclear membrane having been rendered permeable to the antibody after aldehyde fixation of such a neuron.

In the monkey fetus, the cerebellar granule cells contain NNE as a dominant enolase isoenzyme until they have completed their migration and, presumably, established synapses with Purkinje dendrites. At that lime, there is a switch from NNE to NSE (Schmechel et al., $1980 \mathrm{~h})$. A switch of enolase isoenzyme in damaged hypoglossal neurons would represent a metabolic "dedifferentiation" and during regeneration, a "redifferentiation." This change in protein species would be concordant with that in chromatolytic, facial nerve neurons where there is a reappearance of certain proteins that had been found in immature but not older hamsters (Griffith and La Velle, 1971). In contrast, two-dimensional electrophoretic protein patterns of regenerating SCG neurons show that no new proteins, which would suggest a reversion to an immature pattern, are synthesized during regeneration (Hall et al., 1978). The latter study, however, lacks resolution at the cellular level, i.e., the SCG protein pattern represents proteins of neuronal and non-neuronal elements. Second, this model may not be comparable to hypoglossal motor neurons, as SCG neurons may belong to the group of peripheral nerve cells which contain both NNE and NSE (Schmechel et al., $1978 b)$. In such a case, electrophoretic protein patterns might more likely reveal a change in NNE/NSE ratio than a new protein spot.

Because of only a minor increase of NNE immunoreactivity and the low signal to background ratio of NNE staining in hypoglossal neurons following axon injury, we presently cannot conclude that the NNE level during regeneration was an appreciable one, signifying a return to the isoenzyme characteristic of younger neurons.

Our findings of a marked decline and subsequent return to a normal level of NSE immunoreactivity in hypoglossal neurons after axonal injury are reproducible with respect to time course and degree, and correspond to the known time course and extent of hypoglossal nerve regeneration. Furthermore, there is suggestive evidence that immunocytochemically detectable levels of NSE are produced only when cerebellar granule cells have established their full complement of synaptic connections (Schmechel, et al., 1980b). Also, chick ventral horn neurons express NSE immunoreactivity, only after a critical level of functional activity has developed (Maxwell et al., 1982). On the basis of the present study, in conjunction with the two above reports, we propose NSE as a reliable enzymatic indicator of axonal injury, regeneration, and, in particular, of target innervation and reinnervation.

\section{References}

Agranoff, B. W., C. B. Smith, and L. Sokoloff (1980) Regional protein synthesis in rat brain after hypoglossal axotomy. Trans. Am. Soc. Neurochem. 11: 95.

Blinzinger, K., and G. Kreutzberg (1968) Displacement of synaptic terminals from regenerating motoneurons by microglial cells. Z. Zellforsch. 85: 145-157.

Bock, E., and J. Dissing (1975) Demonstration of enolase activity connected to the brain-specific protein 14-3-2. Scand. J. Immunol. (Suppl. 2) 4: 31-36.

Brattgard, S. O., J. E. Edstrom, and H. Hyden (1957) The 
chemical changes in regenerating neurons. J. Neurochem. 1: 316-325.

Cragg, B. G. (1970) What is the signal for chromatolysis? Brain Res. 23: 1-21.

Dietrich, W. D., D. Durham, O. H. Lowry, and T. A. Woolsey (1981) Quantitative histochemical effects of whisker damage on single identified cortical barrels in the adult mouse. J. Neurosci. 1: 929-935.

Grafstein, B. (1975) The nerve cell body response to axotomy. Exp. Neurol. 48: 32-51.

Grafstein, B., and I. G. McQuarrie (1978) Role of the nerve cell body in axonal regeneration. In Neuronal Plasticity, C. W. Cotman, ed., pp. 155-195, Raven Press, New York.

Griffith, A., and A. La Velle (1971) Developmental protein changes in normal and chromatolytic facial nerve nuclear region. Exp. Neurol. 33: 360-371.

Hall, M. E., D. L. Wilson, and G. C. Stone (1978) Changes in protein metabolism following axonotomy: A two-dimensional analysis. J. Neurobiol. 9: 353-366.

Harkonen, M. H. A., and F. C. Kaufman (1974) Metabolic alterations in the axotomized superior cervical ganglion of the rat. I. Energy metabolism. Brain Res. 65: 127-139.

Jacobson, M. (1978) Developmental Neurobiology, Ed. 2, Plenum Press, New York.

Lieberman, A. R. (1971) The axon reaction: A review of the principal features of perikaryal responses to axon injury. Int. Rev. Neurobiol. 14: 49-124.

Marangos, P. J., and D. E. Schmechel (1980) The neurobiology of the brain enolases. In Essays in Neurochemistry and Neuropharmacology, M. B. H. Youdim, W. Lovenberg, D. F. Sharman, and J. R. Lagnado, eds., vol. 4, pp. 212-247, John Wiley and Sons, New York.

Marangos, P. J., C. Zomzely-Neurath, D. C. M. Luk, and C. York (1975a) Isolation and characterization of the nervous system specific protein 14-3-2 from rat brain. J. Biol. Chem. 250: 1884-1901.

Marangos, P. J., C. Zomzely-Neurath, and C. York (1975b) Immunological studies of a nerve specific protein (NSP). Arch. Biochem. Biophys. 170: 289-293.

Marangos, P. J., A. M. Parma, D. E. Schmechel, and F. K. Goodwin (1978a) The developmental profile of neuronal and glial enolase in ral brain. Soc. Neurosci. Abstr. 4: 120.

Marangos, P. J., A. P. Zis, R. L. Clark, and F. K. Goodwin (1978b) Neuronal, non-neuronal and hybrid forms of enolase in brain: Structural, immunological and functional comparisons. Brain Res. 150: 117-133.

Maxwell, G. D., M. C. Whitehead, S. M. Connolly, and P. J.
Marangos (1982) Development of neuron-specific enolase immuno-reactivity in avian nervous tissue in vivo and in vitro. Dev. Brain Res. 3: 401-418.

Moore, B. W., and D. McGregor (1965) Chromatographic and electrophoretic fractionation of soluble proteins of brain and liver. J. Biol. Chem. 240: 1647-1653.

Pickel, V. M., D. J. Reis, P. J. Marangos, and C. ZomzelyNeurath (1976) Immunocytochemical localization of nervous system specific protein (NSP-R) in rat brain. Brain Res. 105: 184-187.

Schmechel, D. E., P. J. Marangos, A. P. Zis, M. Brightman, and F. K. Goodwin (1978a) The brain enolases as specific markers of neuronal and glial cells. Science 199: 313-315.

Schmechel, D. E., P. J. Marangos, and M. Brightman (1978b) Neuron-specific enolase is a molecular marker for peripheral and central neuroendocrine cells. Nature 276: 834-836.

Schmechel, D. E., M. W. Brightman, and J. L. Baker (1980a) Localization of neuron-specific enolase in mouse spinal neurons grown in tissue culture. Brain Res 181: 391-400.

Schmechel, D. E., M. W. Brightman, and P. J. Marangos (1980b) Neurons switch from non-neuronal enolase to neuron-specific enolase during differentiation. Brain Res. 190: 195-214.

Singer, P. A., and S. Mahler (1979) The time course of increased glucose utilization in hypoglossal nucleus neurons during regeneration. Soc. Neurosci. Abstr. 5: 683 .

Sternberger, L. W. (1979) Immunocytochemistry, Ed. 2, John Wiley and Sons, New York.

Sumner, B. E. H. (1976) Quantitative ultrastructural observations on the inhibited recovery of the hypoglossal nucleus from the axotomy response when regeneration in the hypoglossal nerve is prevented. Exp. Brain Res. 26: 141-150.

Watson, W. E. (1968) Observations on the nucleolar and total cell body nucleic acid of injured nerve cells. J. Physiol. (Lond.) 196: 655-676.

Watson, W. E. (1970) Some metabolic responses of axotomized neurones to contact between their axons and denervated muscle. J. Physiol. (Lond.) 210: 321-343.

Wong-Riley, M. T. T., and C. Welt (1980) Histochemical changes in cytochrome oxidase of cortical barrels after vibrissal removal in neonatal and adult mice. Proc. Natl. Acad. Sci. U. S. A. 77: 2333-2337.

Zomzely-Neurath, C. E., and W. A. Walker (1980) Nervous system-specific proteins: 14-3-2 protein, neuron-specific enolase, and S-100 protein. In Proteins of the Nervous System, R. A. Bradshaw and D. M. Schneider, eds., Ed. 2, pp. 1-57, Raven Press, New York. 